Published in final edited form as:

Curr Gastroenterol Rep. 2010 October ; 12(5): 349-357. doi:10.1007/s11894-010-0132-1.

\title{
Mast Cells
}

Terez Shea-Donohue, Jennifer Stiltz, Aiping Zhao, and Luigi Notari

Department of Medicine and Mucosal Biology Research Center, University of Maryland School of Medicine, 20 Penn Street, Baltimore, MD 21201, USA, tdonohue@mbrc.umaryland.edu

\section{Abstract}

Mast cells have been considered for many years to participate specifically in allergic reactions through the release of cytokines, chemokines, proteases, leukotrienes, and bioactive polyamines. Emerging roles for mast cells have been identified recently, which highlight their relevance in both innate and adaptive immunity. Mast cells play a role in many different processes, including clearance of enteric pathogens, food allergies, visceral hypersensitivity, and intestinal cancer. The activation of mast cells can initiate inflammatory reactions that are life-saving in some circumstances (eg, nematode infection) but life-threatening in others (eg, allergy). In recent years, mast cells, their products, and the mechanisms by which mast cell activity can be regulated by the microenvironment are a major area of investigation. The purpose of this review article is to summarize and highlight the latest findings in mast cell biology associated with intestinal homeostasis and pathologies.

\section{Keywords}

Mast cell; Immunity; Nematode; Intestine; Allergy; Serine proteases; Tryptase; PAR2; Cancer; Intestinal barrier; Smooth muscle; Nerves; TNFa; IL-33; IL-13

\section{Introduction}

Mast cells were discovered more than a century ago by Paul Erlich based on the observation of the unique color-changing granules within these cells. They are the progeny of $\mathrm{CD} 34^{+}$ hematopoietic stem cells and have a stringent requirement for stem cell factor (SCF), the ligand for the c-kit receptor (CD117), for differentiation. SCF is elaborated by several cell types including fibroblasts and stromal cells in the small intestine. Although they have a well-defined contribution to allergic reactions, the recognized roles of mast cells have expanded considerably in the past few years to include their contribution to the interplay between gut immunity and gut function, which may be exacerbated in pathologies that feature elevated numbers of mast cells. The renewed interest in mast cells can be linked, in part, to several distinctive attributes of mast cells, including their evolutionarily conserved role in defense, because they are observed in some form in invertebrates as well as in mammals; their constitutive localization to mucosal interfaces that can be augmented during inflammation; and their ability to elaborate a plethora of mediators ranging from preformed proteases and histamine to de novo synthesized cytokines, chemokines, and lipid mediators.

There was an early recognition of morphologically distinct types of mast cells based on tissue localization (connective tissue $[\mathrm{CTMC}]$ and mucosal mast cells $[\mathrm{MMC}]$ ) in mice and

(C) Springer Science+Business Media, LLC 2010

Correspondence to: Terez Shea-Donohue.

Disclosure No potential conflict of interest relevant to this article was reported. 
protease content of tryptase $\left(\mathrm{MC}_{\mathrm{T}}\right)$ or chymase $\left(\mathrm{MC}_{\mathrm{TC}}\right)$ in humans [1•]. This strict classification, however, is somewhat obsolete in humans, with the understanding that mast cell progenitors differentiate into mature cells under the influence of microenvironmental factors that greatly amplify mast cell heterogeneity. The importance of the tissue milieu as a major determinant of mast cell phenotype is an active area of investigation. The fact that mast cells are influenced by the microenvironment suggests that they could be "customized" to perform functions specific to that region. Cell-surface receptor expression on mast cells varies by the state of maturation and the environmental milieu. For example, interleukin (IL)-4 increases expression of fragment crystallizable $\varepsilon$ region (FceR)-I and interferon (IFN)- $\gamma$ induces expression of fragment crystallizable $\gamma$ region (Fc $\gamma \mathrm{R}$ )-I (CD64) [2]. Mast cell granules contain both preformed (eg, histamine and serine proteases) and newly synthesized mediators (eg, leukotrienes), and their release is governed by the activated receptors, the strength of the signal, and the tissue environment. Indeed, the mechanisms or conditions that regulate mast cell degranulation and release of mediators remain unclear, in part, because in vitro studies cannot fully replicate the in vivo environment. Recent advances in mast cell function are summarized in Table 1.

\section{Innate and Adaptive Immunity}

The numbers of resident mast cells in the healthy gut is about $2 \%$ of mucosal cells, but mast cells can be recruited in large numbers in response to an array of stimuli. Homing of mast cell progenitors to the gut involves binding of a $4 \beta 7$ integrins on mast cells to mucosal addressin cell adhesion molecules (MADCAM-1) and vascular cell adhesion molecules (VCAM-1) on endothelial cells. In addition, evidence exists that dendritic cell expression of t-bet, a transcription factor important in the development of polarized T-helper 1 cell (Th1) responses, may also be important for homing of mast cells to mucosal surfaces [3]. Given the location of mast cells at mucosal surfaces and their ability to influence barrier function, it is not surprising that they might function as immunologic "gate keepers." Mast cells express toll-like receptors (TLR) that are important for host defense against the abundant bacteria in the colon. It has been suggested, however, that mast cells can behave like other phagocytic bone marrow-derived cells such as dendritic cells and macrophages, and become less responsive to bacterial stimuli when matured in the colonic environment [4].

Mast cells both elaborate and express receptors for several cytokines, implicating a role as intermediates between innate and adaptive immune response (Fig. 1). Increased numbers of mast cells are observed in the colon of patients with inflammatory bowel disease (IBD) and are an important source of tumor necrosis factor (TNF)- $a$ in colitis. Release of TNF- $a$, IL-1 $\beta$, and granulocyte-macrophage colony-stimulating factor (GM-CSF) promotes dendritic cell migration, maturation, and activation. Mast cells also communicate with both T and B cells. TLR4-mediated release of TNF- $\alpha$ and IL-12 from mast cells in response to lipopolysaccharide (LPS) facilitates the development of the Th1 cytokine profile. In addition, TLR4 activation also promotes IFN- $\gamma$ secretion from natural killer (NK) cells [5], further supporting a role for mast cells in the regulation of innate immunity. The IFN family was expanded recently with the discovery of IFN- $\lambda$, which has three subtypes, including IFN- $\lambda 1$ (IL-29). Although originally linked to viral infections, IFN- $\lambda$ signaling also involves phosphorylation of signal transducers and activators of transcription (STAT) 1 and STAT4 and can downregulate the Th2 cytokine IL-13 [6]. Mast cells can release IL-29 in response to antigenic stimulation or LPS. Under these conditions, release of IL-4 and IL-13, but not of histamine, suggests that IL-29 does not activate mast cells, but rather contributes to mast cell recruitment through the generation of cytokines [7]. This observation is consistent with the belief that there is a specific control of mast cell product release in response to different stimuli, and therefore, knowledge of these mechanisms is important in the design of new therapeutic interventions for enteric inflammation, allergy, and infection. 
When compared to the colon, the small intestine does not have significant bacterial colonization, coincident with a low expression of TLRs in this region. Several other pathogens, however, including enteric nematodes, preferentially colonize the small intestine. There is a continuing interest in nematodes, based on experimental and population studies showing the beneficial effects of infection on autoimmune and allergic diseases that has been linked to abnormal immunoregulatory mechanisms that fail to downregulate polarized Th1, Th2, or Th17 cytokine responses [8]. This interest has fostered investigation into the therapeutic potential of worms or their products. Nematode infection induces a well-known mastocytosis, which is required for clearance of some (eg, Trichinella spiralis), but not all, nematodes. This dependence was challenged by recent data showing that expulsion of $T$. spiralis could occur in the absence of mastocytosis [9]. The increase in mast cell numbers is due, in part, to IL-4, but the effect is not entirely STAT6-dependent, because IL-3 and IL-9 are also important. IL-9 was traditionally associated with Th2 responses and is involved in recruitment and activation of mast cells. The identification of a novel T-helper population, Th9-which expresses high levels of IL-9 in the presence of IL-4 and TGF- $\beta$, suppresses Th2 cytokines [10], and promotesTh17 differentiation and T-regulatory cell function [11] has prompted a reevaluation of the role of IL-9 in immune responses. However, the finding that IL-25 (a major regulator of Th2 responses) also regulates IL-9 expression in Th9 cells [12] supports the contribution of IL-9 to Th2-mediated immunity. IL-4 markedly increases mast cell proliferation and shifts IgE-dependent cytokine production in mature human mast cells toward an increased release of Th2 cytokines. In a recent report, using a model of bone marrow reconstitution in T. spiralis-infected WBB6F1-KitW/KitW-v ( $\left.W / W^{V}\right)$ mast celldeficient mice, it was demonstrated that mast cell production of IL-4 and TNF- $a$ is required for protective and pathologic responses in gastrointestinal helminth infection [13•].

IL-33 (or IL-1F11) is a newly discovered cytokine belonging to the IL-1 family. Recent reports identified IL-33 as ligand for the previously known orphan IL-1 receptor (IL-1R) family member T1/ST2, which is highly expressed on T and mast cells [14]. Several reports in the past year demonstrated that IL-33 is responsible for activating mast cells, with a mechanism that involves stimulating production of IL-5, IL-4, and IL-13 [15-17]. Interestingly, it was reported in a recent publication that during Trichuris muris infection, IL-33 mRNA is expressed early and susceptible mice can be induced to expel the parasite by a regimen of exogenous IL-33 administration [18••]. These data strengthen the hypothesis of a direct involvement of mast cells in the mechanisms that promote gastrointestinal helminth expulsion.

Immune cells, including mast cells, are controlled, in part, by the balance of input derived from positive and negative signals. There is an appreciation that attenuation or cessation of cell function may be regulated by either loss or inactivation of the stimulus or by activation of a counter-balancing inhibitory signal. Loss of inhibitory signals may contribute to unrestrained inflammation characteristic of several autoimmune diseases or to the rapidity of hypersensitivity reactions in anaphylaxis. A number of mast cell receptors contain immunoreceptor tyrosine-based inhibitory motifs (ITIM), now considered part of the inhibitory receptor superfamily. ITIMs can be part of an inhibitory receptor or can be linked functionally or physically to activating receptors or to immunoreceptor tyrosine-based activating motifs (ITAM). The protein gp49B1 is part of the $\mathrm{C} 2$ family of immunoglobulins and contains two ITIMs that result in inhibition of intracellular calcium release, an important step in degranulation as well as release of lipid mediators such as leukotrienes. Binding of the integrin, av $\beta 3$, to gp49B1 leads to inhibition of IgE-mediated activation [19]. SCF activation of c-kit is critical for mast cell growth and maturation and survival, but unchecked activation results in abnormal accumulation of tissue mast cells. Recent studies show that ckit can be downregulated by ligation of CD72 (Lyb-2), a type II transmembrane receptor in the C-type lectin family [20•]. In addition, newly discovered immunoglobulin-like receptor, 
allergy inhibitory receptor (allergin-1), was shown to be present on human mast cells, and to inhibit IgE-mediated mast cell anaphylaxis [21•]. Because control of the release of preformed and newly synthesized mast cell products impacts immune and biologic functions, ITIMs represent a novel therapeutic target for mast cell-mediated pathologies.

\section{Mast Cell Proteases (Peptidases)}

Almost $5 \%$ of the human genome encodes proteases, proteins with enzymatic activity resulting in the cleavage and, therefore, regulation of other proteins. It is not surprising that the contribution of proteases to physiologic and pathophysiologic processes is being actively investigated. Proteases serve many functions including degradation of extracellular matrix proteins, conversion of inactive forms of a protein into their active counterparts, and participation in host defense against intruding pathogens. Many proteases are part of proteolytic cascades, where the product from one reaction acts as the substrate for the next, thereby amplifying an initial signal into a large response. Proteases, one of the major mast cell protein products, are stored in granules and released in response to a variety of stimuli. It was not until 1960 that an enzyme with trypsin-like activity was reported in mast cells and subsequently termed tryptase. In humans, mature $\beta$-tryptase is the major constituent of secretory granules. Activation of mast cells results in a prominent increase in secretion of mature $\beta$-tryptase, which is considered a traditional marker of mast cell degranulation [22•]. Given their abundance, biologic activity, and role as mediators of inflammatory pathologies, there is considerable interest in evolutionary origin of mast cell proteases [23]. The major mast cell proteases are tryptase and chymase, encoded by the mast cell chymase and tryptase multigene loci. The most recent evidence indicates that genes within both loci are found almost exclusively in mammals [24•], although the type I membrane-anchored serine proteases, such as prostasin in invertebrates, may be an ancestral form [25]. There is an acknowledged need for additional studies in genetic variation in mast cell genetics that may contribute to variability in therapeutic responses, particularly tryptases that have an elevated incidence of mutations affecting their function [22•].

As the major protein stored in human mast cells, large amounts of tryptase are released by degranulation, a hallmark feature of a proinflammatory response associated with allergic reactions. The fact that tryptase activates protease-activated receptor-2 $\left(\mathrm{PAR}_{2}\right)$ has exponentially expanded its biologic importance. $\mathrm{PAR}_{2}$ is expressed on many cell types, including epithelial, smooth muscle cells, and nerves, as well as on immune and inflammatory cells, including mast cells and antigen presenting cells. Endogenous serine proteases, such as trypsin, play a well-known physiologic role in digestion; however, recent studies indicate that PARs are critical players in several gut pathologies. Evidence exists linking serine protease activation of PAR to proinflammatory pathologies, including IBD and functional bowel disorders such as irritable bowel syndrome (IBS) [26].

\section{Intestinal Barrier Function}

Increased intestinal permeability is a common outcome of immune-mediated diseases including diabetes, IBS, food allergy, and celiac disease. Although the contribution of mast cells to barrier function in homeostasis is not well defined, they are known to release mediators with documented effects on epithelial barrier function including proteases, histamine, and Th1 (TNF-a, IL-1 $\beta$ ) and Th2 cytokines (IL-4, IL-13) [27].

A novel mediator for mast cell actions on intestinal permeability is mast cell chymase (Mcpt4 is the mouse homologue), which is elaborated by murine connective tissue mast cells located in the submucosa [28]. Groschwitz et al. [29••] demonstrated that both mast cell deficient $\left(\mathrm{Kit}^{\mathrm{W}-\mathrm{sh} / \mathrm{W}-\mathrm{sh}}\right.$ ) and $\mathrm{Mcpt}^{-{ }^{-/}}$mice had increased intestinal permeability coincident with decreased claudin-3 expression. Exposure to human chymase also increased 
cultured epithelial cell permeability, providing further support for a role for mast cell chymase in the regulation of constitutive barrier function. A novel observation was the involvement of mast cell chymase in the control of epithelial migration, adding to the list of functions that may involve mast cells [29••]. To elucidate the mechanism by which chymase regulates permeability, studies were performed to examine epithelial architecture and cell migration; it was determined that $\mathrm{Mcpt}^{-{ }^{-/}}$mice had altered barrier function due to decreased intestinal epithelial cell migration along the villus/crypt axis. WT but not $\mathrm{Mcpt}^{-/-}$mast cells grafted into Wsh mice were able to restore intestinal epithelial cell migration, morphology, and function $[29 \cdot \bullet]$.

Elevated numbers of tissue mast cells are known to alter intestinal mucosal permeability and mastocytosis with accompanying changes in permeability as a common feature of nematode infection [27]. These changes are linked to mouse mast cell protease 1 (mMCP1)-mediated destruction of occludin in T. spiralis infection [30]. More recent data implicated mast cell tryptase activation of $\mathrm{PAR}_{2}$, which is expressed by mast cells and epithelial cells. Activation of $\mathrm{PAR}_{2}$ by tryptase or $\mathrm{PAR}_{2}$ activating peptide (SLIGRL) leads to a redistribution of TJ proteins, ZO-1, occludin, and the rearrangement of F-actin, resulting in increased intestinal permeability [31]. Recent findings show that there is an immune regulation of $\mathrm{PAR}_{2}$ and that infection impacts epithelial and smooth muscle cell responses to available $\mathrm{PAR}_{2}$ agonists by controlling availability of receptor expression (Shea-Donohue, in press).

Although mucosal mast cells have a well-documented effect on permeability in the small intestine, less information exists regarding these effects in the colon. The concentration of bacteria in the colon and the constitutively higher epithelial resistance in this area would argue against the benefits of mast cell-mediated increases in permeability in this region. Indeed, evidence exists that the mast cell approximation to enteric nerves may increase epithelial secretion in the colon [32]. This action may occur in lieu of dramatic increases in permeability that, along with increases in secretion, would constitute an effective and welldocumented antibacterial defense in the small intestine.

\section{Smooth Muscle and Nerve Function}

Mast cells influence intestinal smooth muscle function primarily as a result of their close approximation with enteric nerves. Evidence exists that mast cells can regulate muscle function directly. In certain circumstances, activated mast cells infiltrate into the muscle layer release mediators such as histamine, tryptase, or leukotrienes that directly cause smooth muscle contraction/relaxation [33]. In addition to these well characterized mediators, a recently identified adhesion molecule, cell adhesion molecule-1 (CADM1), expressed by various cell types, promotes communication between nerves or smooth muscle and mast cells [34]. The predominant result of mast cell/nerve/smooth muscle interactions is a hypersensitivity of nerves to stimulation, resulting in elevated smooth muscle contractility. The effect is thought to contribute to the symptoms of IBS, food allergy, and enteric inflammation. There is also evidence that mast cells participate in the fibrogenesis of Crohn's disease though upregulation of chymase, an enzyme that generates mature angiotensin-II by cleavage of its precursor [35•].

\section{Clinical Applications}

Mast cells play a key role in many pathologies; therefore, this review is limited to a discussion of recent advances in a select group of disorders. 


\section{Functional Gastrointestinal Disorders}

Functional dyspepsia and IBS are on the spectrum of functional gastrointestinal disorders estimated to account for $20 \%$ to $50 \%$ of gastroenterology referrals, with an overall incidence in the community of about $1.5 \%$ [36••]. In the absence of a specific pathology, diagnosis of IBS is based on symptoms as defined under the Rome III system. A common feature of IBS is a visceral hypersensitivity that has been ascribed to altered peripheral or central neural processing of stimuli arising from the lumen of the gut. Ample data support an important role for mast cells in the development of visceral hypersensitivity in IBS as a result of the number of released mediators that can interact with and sensitize the sensory and motor neurons [37]. A novel finding was the significant correlation between mast cells in the descending colon and the frequency and severity of symptoms in the upper gut [38]. Stress is considered to be one of the major etiologic factors for IBS, and recent data in an experimental model showed that chronic stress caused the release of norepinephrine, leading to the increased expression of nerve growth factor, a product of mast cell and smooth muscle cell that plays a key role in sensitizing visceral afferent neurons [39•].

The emergence of a subset of IBS patients with a history of enteric infection led to the identification of a postinfectious IBS group (PI-IBS), which has elevated levels of several inflammatory cells including T cells, 5-hydroxytryptamine (5-HT)-containing enterochromaffin cells (EC), and mast cells in the colon. Several excellent reviews on this topic were published recently [36••, 40, 41]. Of interest is that elevated numbers of rectal mast cells was also a feature in non-postinfectious diarrhea-predominant IBS (D-IBS) patients [42]. In a small cohort study, control groups were compared with non-PI-IBS, and PI-IBS patients, 3 years postinfection. There were elevated levels of 5-HT-containing EC cells and intraepithelial lymphocytes (IEL) in non-PI-IBS patients; however, when compared to non-PI-IBS patients, the PI-IBS group demonstrated elevated numbers of mast cells, peptide PYY, and 5-HT-containing EC cells [43•]. These data demonstrate that mast cells are an important component of IBS, with the presence of other immune/inflammatory cells as a distinguishing feature of PI-IBS. This finding is consistent with observations obtained in animal models of IBS as well as in the T. spiralis infection and neonatal inflammation that feature elevated mast cell numbers.

The colon has been the predominant area of interest in IBS, in part because of the ability to assess rectal hypersensitivity in patients, and further because of the relatively easier accessibility of the large intestine. however, increasing attention is being given to mast cell activity in other areas of the gut. D-IBS patients have significantly elevated mast cell numbers in the jejunum with corresponding higher levels of mast cell tryptase, indicating that mucosal inflammation in IBS is not restricted to the lower gut [44]. This idea was extended to show increased numbers of mast cells in the duodenum of both constipationpredominant (C-IBS) and D-IBS patients [45].

\section{Food Allergy}

Developed countries have experienced a rapid rise in allergic disease, with $6 \%$ to $10 \%$ of the pediatric population suffering from food allergies alone [46]. Infiltration of mast cells to the small or large intestine following oral challenge is a common feature observed in all food allergies and may be associated with constipation or diarrhea. Mast cell activation is implicated in the associated dysmotility, in which allergic reactions evoke mast cell infiltration to the mucosal site. A recent study showed that chronic oral exposure to ovalbumin in rats increased the numbers of mast cells in all areas of intestine and colon, resulting in enhanced smooth muscle contractility [47]. 
Clinical studies of children with food allergy linked related chronic constipation to the close association between mast cells and nerve fibers. Children between the ages of 1 and 10 years old suffering from chronic constipation were treated with an oligoantigenic diet for 8 weeks. A comparison of rectal biopsies taken from before and after 8 weeks of the diet showed that the numbers of mast cells and their proximity to nerve fibers was significantly reduced by removal of the allergen from the diet. On the other hand, sphingosine 1-phosphate (S1P), a ligand for S1P receptors that modulates leukocyte trafficking, was identified as a potential therapeutic target for allergy-induced diarrhea. In an experimental model of allergic diarrhea, mice treated with FTY720, an inhibitor of S1P signaling, exhibited an reduction of $\mathrm{CD}^{+}{ }^{+} \mathrm{T}$-cell migration and impaired mast cell infiltration to the large intestine [48].

It appears that a biphasic response occurs in food allergy. Phase I is the period of specific transcellular antigen transport before mast cell activation through crosslinking IgE/CD23 receptors (FceRII) on mast cells. Phase II is mast cell activation, during which mast cell mediators such as histamine, prostaglandin, and proteases are released, causing epithelial ion secretion and increased epithelial permeability. Oral antigen-induced intestinal anaphylaxis is an experimental model of food allergy because of the common occurrence of mastocytosis, intestinal permeability, and intravascular leakage. Recent reports indicate an important role for IL-9 in mast cell-mediated responses in food allergy; IL- $9^{-/-}$mice failed to develop oral antigen-induced intestinal anaphylaxis, although overexpression of IL-9 predisposed to intestinal anaphylaxis and sensitization to oral antigen. Indeed, IL-9stimulated mast cell activation leads to release of histamine and proteases that contribute to the enhanced intestinal permeability that is critical for sensitization to oral antigens [49••]. Of interest was that this effect was independent of IL-4/IL-13 and STAT6-signaling. It should also be noted that IL-9 involvement in antigen-induced anaphylaxis was dependent on the route of antigenic sensitization. Oral antigen and systemic anaphylaxis required IgE, mast cells, and IL-9, whereas parenteral antigen-induced anaphylaxis was an IL-9 independent pathway [50].

\section{Cancer}

Colon cancers are the third leading cause of cancer-related deaths in industrialized regions and generally develop from nonmalignant adenomatous polyps. Mast cells and T-regulatory (Treg) cells are both involved in tumorigenesis associated with colon cancer. In the past 3 years, the work performed by Gounaris et al. [51] focused on mast cells as an essential hematopoietic component in polyp development. Genetic or pharmacologic depletion of mast cells resulted in remission of polyps. Altered Treg phenotype is also a factor in cancer. IL-10-producing Treg cells are beneficial because they suppress inflammation, a critical component of tumor progression. In colon cancer, Treg cells, which expand in adenomatous polyps, no longer produce IL-10 [52••]. In addition, Treg cells normally suppress mast cell activity via IL-10; however, in cancer, Treg cells no longer suppress mastocytosis [53]. Treg cells in polyps were found to "switch" from producing IL-10 to IL-17, thereby promoting a proinflammatory rather than an immunosuppressive environment. Mast cells were shown to be recruited by these "IL-17 switched" Treg cells, further increasing the proinflammatory environment.

\section{Conclusions}

Mast cells are functionally diverse cells that have a constitutive presence atmucosal surfaces and elaborate an impressive array of mediators, making them an attractive therapeutic target. There is particular interest recently in the mast cell proteases because of their welldocumented ability to alter intestinal permeability, a key factor in several GI autoimmune/ inflammatory pathologies. A feature that mast cells have in common with other hematopoietic-derived cells is a flexible phenotype that impacts function. In this respect, 
mast cells help shape development of tissue environment, an attribute consistent with their role in the transition from innate to adaptive immune responses. Recruitment of mast cell progenitor cells to mucosal surfaces results in maturation in a specific milieu, and polarization toward a Th1/Th17 or Th2 environment, therefore, will determine the nature and/or amount of mediators released. In this regard, a growing number of cytokines impact mast cells, with an expanding role for cytokines such as IL-9 and IL-33. Appreciation is also enhanced for factors involved in controlling or limiting activity of mast cells through receptors that contain inhibitory motifs (ITIM). The role of mast cells in IBS and food allergy is well-documented and represents a convergence of mast cell actions on immune and intestinal function.

\section{Acknowledgments}

Dr. Terez Shea-Donohue, Dr. Aiping Zhao, and Dr. Luigi Notari are supported by National Institutes of Health RO1 grants. The authors acknowledge the support of RO1 AI49316, which was awarded to Dr. Shea-Donohue. Ms. Jennifer Stiltz is supported by a T32 training grant.

\section{References}

Papers of particular interest, published recently, have been highlighted as:

- Of importance

•- Of major importance

1. Heib V, Becker M, Taube C, Stassen M. Advances in the understanding of mast cell function. Br J Haematol. 2008; 142:683-694. [PubMed: 18513284] . This excellent review article highlights recent advances in human and murine mast cell function, focusing on their role in innate and adaptive immunity. It also includes information on mast cell subsets, and describes pertinent tools in mast cell research, including animal models.

2. Stone KD, Prussin C, Metcalfe DD. IgE, mast cells, basophils, and eosinophils. J Allergy Clin Immunol. 2010; 125:S73-S80. [PubMed: 20176269]

3. Alcaide P, Jones TG, Lord GM, et al. Dendritic cell expression of the transcription factor T-bet regulates mast cell progenitor homing to mucosal tissue. J Exp Med. 2007; 204:431-439. [PubMed: 17296784]

4. Bischoff SC, Lorentz A, Schwengberg S, et al. Mast cells are an important cellular source of tumour necrosis factor- $a$ in human intestinal tissue. Gut. 1999; 44:643-652. [PubMed: 10205200]

5. Vosskuhl K, Greten TF, Manns MP, et al. Lipopolysaccharide-mediated mast cell activation induces IFN-gamma secretion by NK cells. J Immunol. 2010; 185:119-125. [PubMed: 20511546]

6. Jordan WJ, Eskdale J, Srinivas S, et al. Human interferon lambda-1 (IFN-lambda1/IL-29) modulates the Th1/Th2 response. Genes Immun. 2007; 8:254-261. [PubMed: 17361203]

7. He S, Zhang H, Chen H, Yang H, et al. Expression and release of IL-29 by mast cells and modulation of mast cell behavior by IL-29. Allergy. 2010 Epub ahead of print.

8. Rook GA. Review series on helminths, immune modulation and the hygiene hypothesis: the broader implications of the hygiene hypothesis. Immunology. 2009; 126:3-11. [PubMed: 19120493]

9. Blum LK, Thrasher SM, Gagliardo LF, et al. Expulsion of secondary Trichinella spiralis infection in rats occurs independently of mucosal mast cell release of mast cell protease II. J Immunol. 2009; 183:5816-5822. [PubMed: 19812197]

10. Dardalhon V, Awasthi A, Kwon H, et al. IL-4 inhibits TGF-beta-induced Foxp3+ T cells and, together with TGF-beta, generates IL-9+ IL-10+ Foxp3(-) effector T cells. Nat Immunol. 2008; 9:1347-1355. [PubMed: 18997793]

11. Elyaman W, Bradshaw EM, Uyttenhove C, et al. IL-9 induces differentiation of TH17 cells and enhances function of FoxP3+ natural regulatory T cells. Proc Natl Acad Sci U S A. 2009; 106:12885-12890. [PubMed: 19433802]

12. Angkasekwinai $\mathrm{P}$, Park $\mathrm{H}$, Wang $\mathrm{YH}$, et al. Interleukin 25 promotes the initiation of proallergic type 2 responses. J Exp Med. 2007; 204:1509-1517. [PubMed: 17562814] 
13. Ierna MX, Scales HE, Saunders KL, Lawrence CE. Mast cell production of IL-4 and TNF may be required for protective and pathological responses in gastrointestinal helminth infection. Mucosal Immunol. 2008; 1:147-155. [PubMed: 19079172] . In this study, the authors demonstrated, with elegant reconstitution experiments, the impaired clearance of the enteric helminth Trichinella spiralis observed in mast cell-deficient mice is associated with a lack of mast cell release of TNFa and IL-4. Further, in the same study the authors define the importance of the same mast cellderived mediators in the development and degree of parasite-associated enteropathy.

14. Schmitz J, Owyang A, Oldham E, et al. IL-33, an interleukin-1-like cytokine that signals via the IL-1 receptor-related protein ST2 and induces T helper type 2-associated cytokines. Immunity. 2005; 23:479-490. [PubMed: 16286016]

15. Castellani ML, Kempuraj D, Salini V, et al. The latest interleukin: IL-33 the novel IL-1-family member is a potent mast cell activator. J Biol Regul Homeost Agents. 2009; 23:11-14. [PubMed: 19321041]

16. Liew FY, Pitman NI, McInnes IB. Disease-associated functions of IL-33: the new kid in the IL-1 family. Nat Rev Immunol. 2010; 10:103-110. [PubMed: 20081870]

17. Xu D, Jiang HR, Kewin P, et al. IL-33 exacerbates antigen-induced arthritis by activating mast cells. Proc Natl Acad Sci U S A. 2008; 105:10913-10918. [PubMed: 18667700]

18••. Humphreys NE, Xu D, Hepworth MR, et al. IL-33, a potent inducer of adaptive immunity to intestinal nematodes. J Immunol. 2008; 180:2443-2449. [PubMed: 18250453] . In this experimental article the authors describe, for the first time, the roles of IL-33 as a potent inducer of adaptive immunity to Trichuris muris, an enteric nematode belonging to the same clade as $\mathrm{T}$. spiralis. The authors show that IL-33 is highly expressed during early phases of parasite infection. Furthermore, it is demonstrated that exogenous administration of IL-33 is sufficient to induce helminth expulsion, and that infection-related pathologic changes are independent of adaptive immunity.

19. Castells MC, Klickstein LB, Hassani K, et al. gp49B1-alpha(v) beta3 interaction inhibits antigeninduced mast cell activation. Nat Immunol. 2001; 2:436-442. [PubMed: 11323698]

20•. Kataoka TR, Kumanogoh A, Bandara G, et al. CD72 negatively regulates KIT-mediated responses in human mast cells. J Immunol. 2010; 184:2468-2475. [PubMed: 20100931] . Inhibition/attenuation of mast cell activation is an emerging area. In this study, the authors show that the ITIM-containing receptor CD72 can downregulate c-KIT-mediated functions, including proliferation and protease production.

21 . Hitomi K, Tahara-Hanaoka S, Someya S, et al. An immunoglobulin-like receptor, Allergin-1, inhibits immunoglobulin E-mediated immediate hypersensitivity reactions. Nat Immunol. 2010; 11:601-607. [PubMed: 20526344] . The regulation of mast cells in hypersensitivity reactions takes a major step forward with the identification of Allergin-1, which contains an ITIM domain and coligates with FceRI to inhibit IGE-mediated, mast cell-dependent anaphylaxis.

22• Trivedi NN, Caughey GH. Mast cell peptidases: chameleons of innate immunity and host defense. Am J Respir Cell Mol Biol. 2010; 42:257-267. [PubMed: 19933375] . This article is a timely review on the clinical importance of mast cell proteases and includes an historical time line of milestones in the research of chymase and tryptase.

23. Crivellato E, Ribatti D. The mast cell: an evolutionary perspective. Biol Rev Camb Philos Soc. 2010; 85:347-360. [PubMed: 19961471]

24- Reimer J, Samollow P, Hellman L. High degree of conservation of the multigene tryptase locus over the past 150-200 million years of mammalian evolution. Immunogenetics. 2010; 62:369382. [PubMed: 20383634] . This original paper presents an analysis of the multigene tryptase locus across several species to better understand the conservation of mast cell proteases during the course of evolution.

25. Caughey GH. Mast cell tryptases and chymases in inflammation and host defense. Immunol Rev. 2007; 217:141-154. [PubMed: 17498057]

26. Coughlin SR, Camerer E. Participation in inflammation. J Clin Invest. 2003; 111:25-27. [PubMed: 12511583]

27. Madden KB, Yeung KA, Zhao A, et al. Enteric nematodes induce stereotypic STAT6-dependent alterations in intestinal epithelial cell function. J Immunol. 2004; 172:5616-5621. [PubMed: 15100305] 
28. Miller HR, Pemberton AD. Tissue-specific expression of mast cell granule serine proteinases and their role in inflammation in the lung and gut. Immunology. 2002; 105:375-390. [PubMed: 11985658]

29••. Groschwitz KR, Ahrens R, Osterfeld H, et al. Mast cells regulate homeostatic intestinal epithelial migration and barrier function by a chymase/Mcpt4-dependent mechanism. Proc Natl Acad Sci U S A. 2009; 106:22381-22386. [PubMed: 20018751] . This study shows a novel role for a mast cell product Mcpt4, which regulates intestinal barrier homeostasis and function. In Mcpt4deficient mice, impaired intestinal barrier function was the result of altered migration of cells along the crypt to villus axis, altered morphology, and dysregulated claudin 3 expression.

30. McDermott JR, Bartram RE, Knight PA, et al. Mast cells disrupt epithelial barrier function during enteric nematode infection. Proc Natl Acad Sci U S A. 2003; 100:7761-7766. [PubMed: 12796512]

31. Jacob C, Yang PC, Darmoul D, et al. Mast cell tryptase controls paracellular permeability of the intestine: role of protease-activated receptor 2 and beta-arrestins. J Biol Chem. 2005; 280:3193631948. [PubMed: 16027150]

32. Sutton TL, Zhao A, Madden KB, et al. Anti-inflammatory mechanisms of enteric Heligmosomoides polygyrus infection against trinitrobenzene sulfonic acid-induced colitis in a murine model. Infect Immun. 2008; 76:4772-4782. [PubMed: 18644879]

33. Bischoff S. Physiological and pathophysiological functions of intestinal mast cells. Semin Immunopathol. 2009; 31:185-205. [PubMed: 19533134]

34. Ito A, Hagiyama M, Oonuma J. Nerve-mast cell and smooth muscle-mast cell interaction mediated by cell adhesion molecule-1, CADM1. J Smooth Muscle Res. 2008; 44:83-93. [PubMed: 18552455]

35•. Suekane T, Ikura Y, Watanabe K, et al. Phenotypic change and accumulation of smooth muscle cells in strictures in Crohn's disease: relevance to local angiotensin II system. J Gastroenterol. 2010 Epub ahead of print. This article reviews the recent studies showing that CADM1, a member of the immunoglobulin super-family and expressed by a variety of cells, mediates the interactions between nerve-mast cell and smooth muscle-mast cell.

36••. Spiller R, Garsed K. Postinfectious irritable bowel syndrome. Gastroenterology. 2009; 136:19791988. [PubMed: 19457422] . This article is one of several recent reviews on this topic that provides a very thorough discussion of the current knowledge and opinion on epidemiology, clinical presentation, mechanisms, differential diagnosis, and management. This report also provides additional resources, including a list of publications and pertinent details on the incidence of postinfectious IBS.

37. Barbara G, Wang B, Stanghellini V, et al. Mast cell-dependent excitation of visceral-nociceptive sensory neurons in irritable bowel syndrome. Gastroenterology. 2007; 132:26-37. [PubMed: 17241857]

38. Cremon C, Gargano L, Morselli-Labate AM, et al. Mucosal immune activation in irritable bowel syndrome: gender-dependence and association with digestive symptoms. Am J Gastroenterol. 2009; 104:392-400. [PubMed: 19174797]

39•. Winston JH, Xu GY, Sarna SK. Adrenergic stimulation mediates visceral hypersensitivity to colorectal distension following heterotypic chronic stress. Gastroenterology. 2010; 138:294-304. [PubMed: 19800336] . This study demonstrated that chronic stress-induced visceral hypersensitivity in rats is mediated by adrenergic-stimulated release of norepinephrine, resulting in increased expression of nerve growth factor, which in turn sensitizes the visceral afferent neurons.

40. Barbara G, Cremon C, Pallotti F, et al. Postinfectious irritable bowel syndrome. J Pediatr Gastroenterol Nutr. 2009; 48(Suppl 2):S95-S97. [PubMed: 19300138]

41. Ohman L, Simren M. Pathogenesis of IBS: role of inflammation, immunity and neuroimmune interactions. Nat Rev Gastroenterol Hepatol. 2010; 7:163-173. [PubMed: 20101257]

42. Lee KJ, Kim YB, Kim JH, et al. The alteration of enterochromaffin cell, mast cell, and lamina propria T lymphocyte numbers in irritable bowel syndrome and its relationship with psychological factors. J Gastroenterol Hepatol. 2008; 23:1689-1694. [PubMed: 19120860]

43•. Kim HS, Lim JH, Park H, Lee SI. Increased immunoendocrine cells in intestinal mucosa of postinfectious irritable bowel syndrome patients 3 years after acute Shigella infection-an 
observation in a small case control study. Yonsei Med J. 2010; 51:45-51. [PubMed: 20046513] . Although reporting on a very small sample, this article provides unique information about longterm changes in mucosal immunology in postinfectious IBS.

44. Guilarte M, Santos J, de Torres I, et al. Diarrhoea-predominant IBS patients show mast cell activation and hyperplasia in the jejunum. Gut. 2007; 56:203-209. [PubMed: 17005763]

45. Walker MM, Talley NJ, Prabhakar M, et al. Duodenal mastocytosis, eosinophilia and intraepithelial lymphocytosis as possible disease markers in the irritable bowel syndrome and functional dyspepsia. Aliment Pharmacol Ther. 2009; 29:765-773. [PubMed: 19183150]

46. Yu LC-H. The epithelial gatekeeper against food allergy. Pediatr Neonatol. 2009; 50:247-254. [PubMed: 20025136]

47. Traver E, Torres R, de Mora F, Vergara P. Mucosal mast cells mediate motor response induced by chronic oral exposure to ovalbumin in the rat gastrointestinal tract. Neurogastroenterol Motil. 2010; 22:e34-e43. [PubMed: 19682267]

48. Kurashima Y, Kunisawa J, Higuchi M, et al. Sphingosine 1-phosphate-mediated trafficking of pathogenic Th2 and mast cells for the control of food allergy. J Immunol. 2007; 179:1577-1585. [PubMed: 17641024]

49••. Forbes EE, Groschwitz K, Abonia JP, et al. IL-9- and mast cell-mediated intestinal permeability predisposes to oral antigen hypersensitivity. J Exp Med. 2008; 205:897-913. [PubMed: 18378796]. This study identified an important role for IL-9 in oral antigen hypersensitivity. IL-9-deficient mice do not develop intestinal anaphylaxis in response to oral antigen, whereas overexpression of IL-9 in the intestine leads to an anaphylaxis phenotype with intestinal mastocytosis, intestinal permeability, and intravascular leakage. The intestinal response to IL-9 requires mast cells, further supporting the contribution of IL-9 to mast-cell responses during food allergy.

50. Osterfeld H, Ahrens R, Strait R, et al. Differential roles for the IL-9/IL-9 receptor [alpha]-chain pathway in systemic and oral antigen-induced anaphylaxis. J Allergy Clin Immunol. 2010; 125:469-476. [PubMed: 20159257]

51. Gounaris E, Erdman SE, Restaino C, et al. Mast cells are an essential hematopoietic component for polyp development. Proc Natl Acad Sci U S A. 2007; 104:19977-19982. [PubMed: 18077429]

52••. Gounaris E, Blatner NR, Dennis K, et al. Cells shift from a protective anti-inflammatory to a cancer-promoting proinflammatory phenotype in polyposis. Cancer Res. 2009; 69:5490-5497. [PubMed: 19570783] . Previous reports indicated that Tregs reduced cancer-associated inflammation and therefore provide protection. Using a murine model of hereditary colon cancer, the authors showed that Tregs begin to produce IL-17, which causes inflammation. Although non-IL-17-producing Tregs were found to reduce focal mastocytosis, these altered IL-17producing Tregs promoted focal mastocytosis. This step is critical to the tumor-promoting inflammatory response in colon cancer.

53. Blatner NR, Bonertz A, Beckhove P, et al. In colorectal cancer mast cells contribute to systemic regulatory T-cell dysfunction. Proc Natl Acad Sci U S A. 2010; 107:6430-6435. [PubMed: 20308560] 


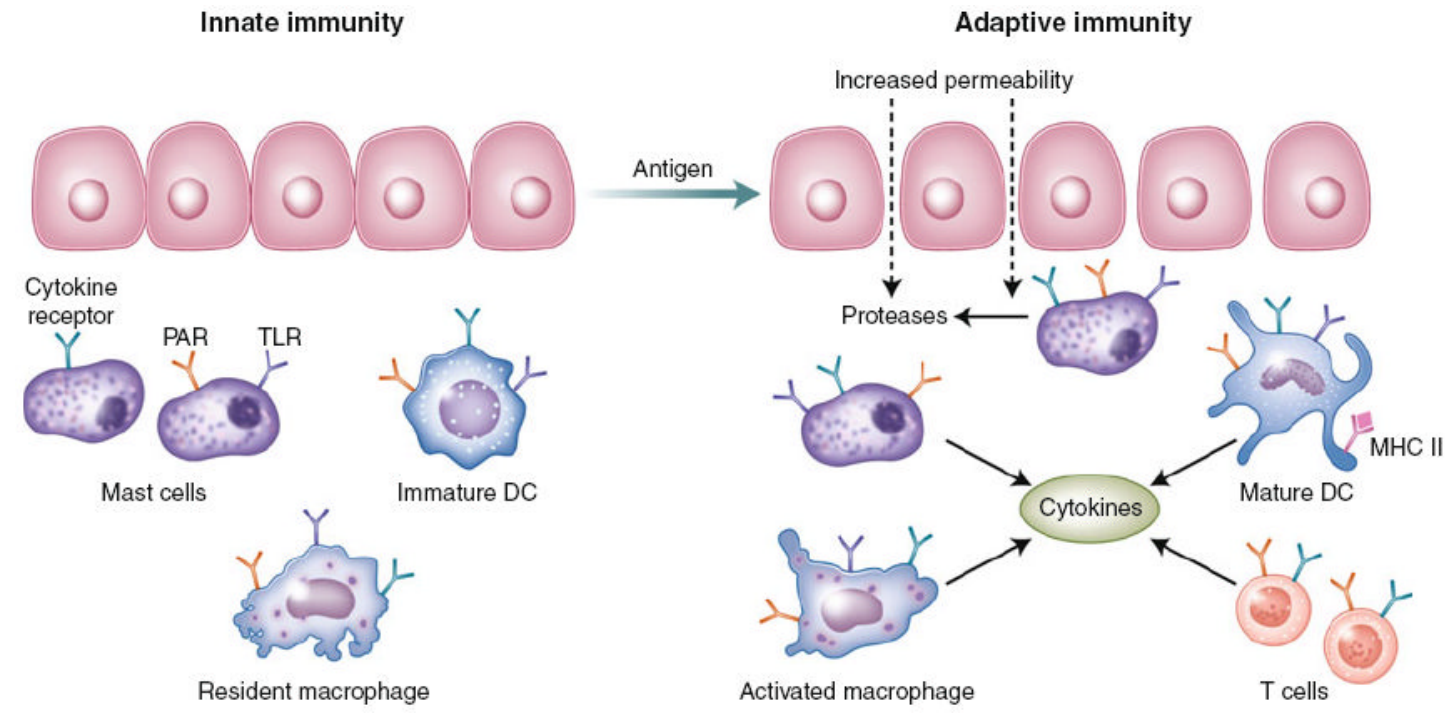

Fig. 1.

Mast cells play an important role in the link between innate and adaptive immunity. Hematopoietic-derived cells, including the antigen-presenting dendritic cells (DC) and macrophages as well as mast cells, all express toll-like receptors (TLR) and proteaseactivated receptors (PARs), which are implicated in the immune tolerance to commensal bacteria and in the mucosal defense against pathogenic organisms in the lumen. Mast cells release proteases that play a key role in the increased permeability, facilitating exposure of immune cells to mucosal antigens. The subsequent release of mediators (eg, chemokines) from epithelial cells and immune cells is important in adaptive immunity, involving T-cell recruitment. The cytokine profile (Th1, Th2, Th9, Th17) is determined by the nature of the antigenic stimulation, and the cytokine environment is an important determinant of mast cell function. MHC—major histocompatibility complex 
Table 1

Summary of recent advances in mast cell function

\begin{tabular}{|c|c|}
\hline Study & Observation \\
\hline Heib et al. [1•], Alcaide et al. [3] & $\begin{array}{l}\text { Control of mast cell phenotype and function by the } \\
\text { tissue environment }\end{array}$ \\
\hline $\begin{array}{l}\text { Vosskuhl et al. [5], He et al. [7], Blum et al. [9], Ierna et al. [13•], Castellani et al. [15], } \\
\text { Liew et al. [16], Humphreys et al. [18••] }\end{array}$ & $\begin{array}{l}\text { Cytokine (IFN- } \gamma, \text { IL- } 9, \text { IL-33, IL-25, TNF) } \\
\text { regulation of mast cell function }\end{array}$ \\
\hline Kataoka et al. [20•], Hitomi et al. [21•] & Novel inhibitory control of mast cell activity \\
\hline Crivellato and Ribatti [23],Reimer et al. [24•] & Genetic regulation of mast cell proteases \\
\hline Groschwitz et al. [29••], Bischoff [33] & Mast cells and intestinal barrier homeostasis \\
\hline Bischoff [33], Ito et al. [34], Suekane et al. [35•], Barbara et al. [40], Traver et al. [47] & $\begin{array}{l}\text { Mast cell effects on smooth muscle function and } \\
\text { fibrogenesis }\end{array}$ \\
\hline $\begin{array}{l}\text { Spiller and Garsed [36••], Barbara et al. [37], Cremon et al. [38], Winston et al. [39•], } \\
\text { Barbara et al. [40], Ohman and Simren [41], Lee et al. [42], Kim et al. [43•], Guilarte et } \\
\text { al. [44], Walker et al. [45] }\end{array}$ & Small intestinal mast cells and IBS symptoms \\
\hline $\begin{array}{l}\text { Yu [46], Traver et al. [47], Kurashima et al. [48], Forbes et al. [49••], Osterfeld et al. } \\
\text { [50] }\end{array}$ & Mast cell mediators in food allergy \\
\hline Gounaris et al. [51, 52••], Blatner et al. [53] & Immune regulation of mast cells in cancer \\
\hline
\end{tabular}

IFN interferon, $I L$ interleukin, $T N F$ tumor necrosis factor 